\title{
FAKTOR LINGKUNGAN DALAM MANAGEMEN PUBLIK
}

\author{
Asep Sumaryana \\ Staf Pengajar Jurusan Administrasi Negara, FISIP Universitas Padjadjaran, \\ Jl. Raya Bandung-Sumedang, Km 21 Sumedang \\ E-mail: asepsumaryana_asum@yahoo.com
}

\begin{abstract}
ABSTRAK. Managemen tidaklah berdiri sendiri, ada lingkungan yang tidak dapat dilepaskan darinya. Lingkungan ini memengaruhi bagaimana managemen dijalankan. Dalam managemen publik pun seperti demikian adanya. Kepuasan publik yang diharapkan dapat diberikan dalam konteks pelayanan publik seringkali luput. Hal demikian berkaitan dengan sejumlah aktor lingkungan yang ada di dalamnya. Tidak heran jika kemudian pelayanan publik menjadi rendah dan mengecewakan. Kapasitas manager publik menjadi penting dalam menjalankan managemennya. Kapasitas yang baik dapat menghindari pengaruh yang menyebabkan kinerjanya menjadi buruk, namun pengaruh yang mendorong kinerja membaik perlu terus dipacu. Kondisi tersebut memudahkan keluhan publik dapat direspons cepat dan perubahan managerial dapat terus dijalankan lebih cepat. Responsivitas semacam ini akan mengubah persepsi publik atas praktik pelayanan publik yang lamban menjadi cepat tanggap sehingga kepuasan publik dapat diperbaiki secara sistematis.
\end{abstract}

Kata Kunci : Lingkungan dan Managemen Publik

\section{ENVIRONMENT FACTOR IN PUBLIC MANAGEMENT}

ABSTRACT. Management dependency with environment. Evironment an be influent to managerial operating, like in public management. Public satisfaction in public service often less because onecting with environtmen actors. There fore public service far away from public satisfaction. Capacity of public manager more important in management regulating. Good capacity can be avoid to influence for increase performance organisations. That conditions, public voice more easily and can appreciated and changed management more quickly. Responscivity must change public perceptions on sluggish of public service, and become driving for recovery public satisfaction.

Keysword : Environment and public management

\section{PENDAHULUAN}

Jika Donovan ( 1991:11-12) mendefinisikan managemen sebagai proses kegiatan yang dilaksanakan pada organisasi tertentu sebagai rangkaian skills dan tugas, maka itu akan terkait dengan kegiatan planning, organizing, actuating dan controlling seperti yang dikonsepkan George Robert Terry atau Luther Gullick ${ }^{1}$ dengan akronim POSDCORB-nya. Dengan demikian, skills dan tugas tersebut meliputi berbagai hal mulai dariperencanaan sampai pengawasan ataupun pengangggaran.

Managemen disebutkan juga sebagai seni dan ilmu yang berarti kepemilikan ilmunya tidak

\footnotetext{
${ }^{1}$ keduanya dapat dibaca dalam Pasolong (2008:84-86)
}

serta merta langsung dapat dijalankan dalam roda organisasi, diperlukan seni untuk menjalanlankan roda organisasi. Keduanya menjadi penting untuk dipadukan karena ilmu sebagai pengarah sementara seni sebagi penggeraknya. Demikian halnya dalam organisasi publik, persoalan managerial ini menjadi penting supaya kegiatannya dapat berjalan dari mulai perencanaan sampai pengawasan dan evaluasi.

Dalam managemen publik, aktivitasnya diaarahkan untuk dapat memberikan manfaat kepada publik, dan ini berbeda dengan managemen bisnis yang diarahkan untuk profit making. Namun dalam managemen publik, kehadiran kebijakan menjadi penting sebagai acuan aparat publik untuk menjalankan tugasnya. Shafritz (1991:xi) menganggap jika managemen 
publik dengan kebijakan publik berada pada sisi yang tumpang tindih. Pembedaannya diibaratkan sebagai sistem otak dan saraf sementara managemen publik sistem jantung dengan sirkulasi darah dalam tubuh. Dari pandangan ini, kebijakan publik dapat dipandang sebagai kontruksi yang berperan memagari aktivitas aparat dengan pejabat publik untuk melaksanakan tugasnya. Sedangkan managemen publik terletak pada upaya pelaksanaan tugasnya tersebut.

Dari pandangan diatas, managemen publik tidak ada bedanya dengan managemen secara umum. Dalam pelaksanaannya, managemen ini berbasis kebijakan serta bergerak untuk memberikan pelayanan publik. Dengan basis kebijakan, sepatutnya managemen publik dapat memberikan manfaat yang besar bagi masyarakat yang dilayaninya. Namun dalam banyak kenyataan, kelambanan memberikan pelayanan publik dengan beragam penyimpangannya senantiasa menjadi berita yang dikonsumsi publik.

Jika dalam managemen, perencanaan menjadi pilar pertama dan utama, maka beragam kelambanan dan penyimpangan dapat dikaitkan dengan perencanaan yang tidak matang atau tidak mempertimbangkan beragam aspek yang terkait. Mintzberg (1994:37) memandang jika perencanaan mesti mempertimbangkan faktor social responsibility. Dengan pertimbangan ini, penempatan aparat pelaksana yang bertugas di lapangan akan dipertimbangkan berdasarkan the right man in the right place.

\section{PERSOALAN LINGKUNGAN}

Ketidak-tepatan managemen publik dalam melaksanakan tugas bisa saja disebabkan karena beragam pengaruh yang disebabkan lingkungan yang ada. Sebagai sebuah sistem yang terbuka, sebuah organisasi tidak lepas kaitannya dengan lingkungan. Perhubungan ini menjadikan managemen turut terpengaruhi sehingga dapat bekerja lamban ataupun cepat sesuai dengan lingkungannya.

Saefullah (1992:32) melihat lingkungan dalam bentuk fisik, agama, social-ekonomi dan karakteristik social budaya yang dianut masyarakat setempat. Itu berarti lingkungan tidak diabaikan keberadaannya. Dalam kehidupan managemen, lingkungan memengaruhi melalui personal yang terlibat didalamnya. Demikian halnya dalam pelaksanaan tugas negara oleh sebuah organisasi publik. Tidak heran jika pelayanan menjadi lamban, bancakan anggaran sering terjadi menyertai korupsi dan manipulasi lainnya.

Menurutnya, lingkungan dapat dibagi menjadi dua lingkungan besar, yakni (1) lingkungan fisik dan (2) non-fisik. Lingkungan fisik biasanya lebih bersifat statis, sehingga pengaruhnya relatif tetap dan dapat diantisipasi dari mulai proses penyusunan kebijakan. Sementara lingkungan non-fisik bersifat dinamis. Lingkungan non fisik tidak hanya melingkungi pribadi namun juga dalam pusaran organisasi. Dalam lingkungan organisasi, tampaknya lingkungan lebih bersifat dinamis sehingga interaksi lingkungan dengan organisasi akan lebih saling mempengaruhi secara intensif.

Griffin (1996:70) membagi lingkungan sebuah organisasi menjadi 13 kelompok seperti dapat dilihat pada gambar berikut :

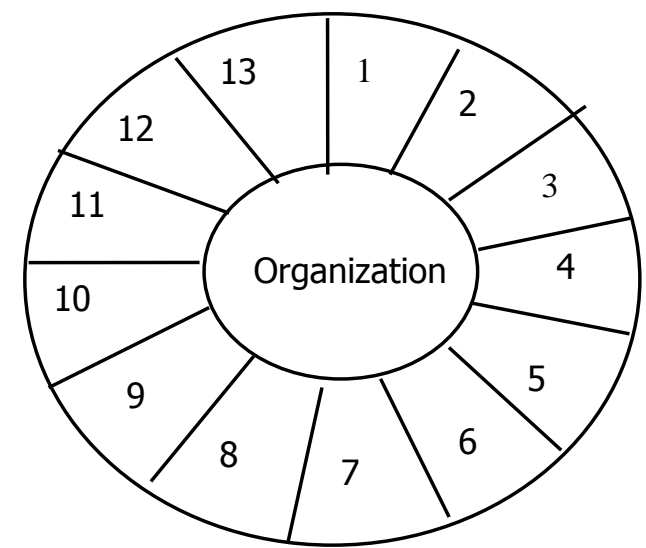

1. Creditor

2. Customers

3. Local Community

4. Supplier

5. Employees

6. Interest groups

7. Trade Associations

8. Owners/Investor

9. Courts

10. Colleges and Universities

11. Foreign Government

12. State/Federal Government

Gambar 1. Lingkungan Organisasi, Griffin (1995:113) 
Dilihat aspek yang melingkungi organisasi, maka setiap organisasi berada dalam pertarungan kepentingan lingkungannya. Dengan adanya tarik menarik kepentingan dalam managemen publik, pemerintahan pun akan menjadi tersendat apabila tidak mempertimbangkan posisi serta kondisi lingkungan yang mengitarinya. Dalam konteks tersebut, manusia dianggap sebagai aspek lingkungan yang dapat memengaruhi lingkungan yang ada, seperti disebutkan Soemarwoto (1997:26).

Dalam kaitannya dengan lingkungan tersebut, Bryson (2000:118-119) membagi lingkungan menjadi dua yakni lingkungan internal dan eksternal. Dengan merujuk Pflaum dan Dedmont, Bryson (2000;141-143) mengelompokkan lingkungan eksternal menjadi enam (6) komponen, yaitu : (1) isu dan kecenderungan yang berkaitan dengan pajak. (2) perubahan nilai sosial dan politik, (3) kecenderungan komputasi, komunikasi dan sistem informasi. (4) peningkatan dalam beban tanggung jawab dan manajemen resiko, (5) perawatan kesehatan. (6) isu-isu lainnya seperti pemulihan akibat bencana dan kehamilan di usia muda.

Lingkungan internal terbagi menjadi tiga yaitu (1) sumber daya (input) seperti gaji, suplai, infrastruktur, personalia; (2) strategi (proses); dan (3) kinerja (output). Dalam dua komponen yang disebutkan terakhir umumnya organisasi publik tidak memiliki informasi dan gagasan yang jelas tentang apa yang yang menjadi strategi sekarang serta bagaimana kinerjanya.

Lebih mudahnya, hubungan pengaruh lingkungan terhadap pemerintah sebagai organisasi publik digambarkan Bryson (2000: 121) sebagai berikut :

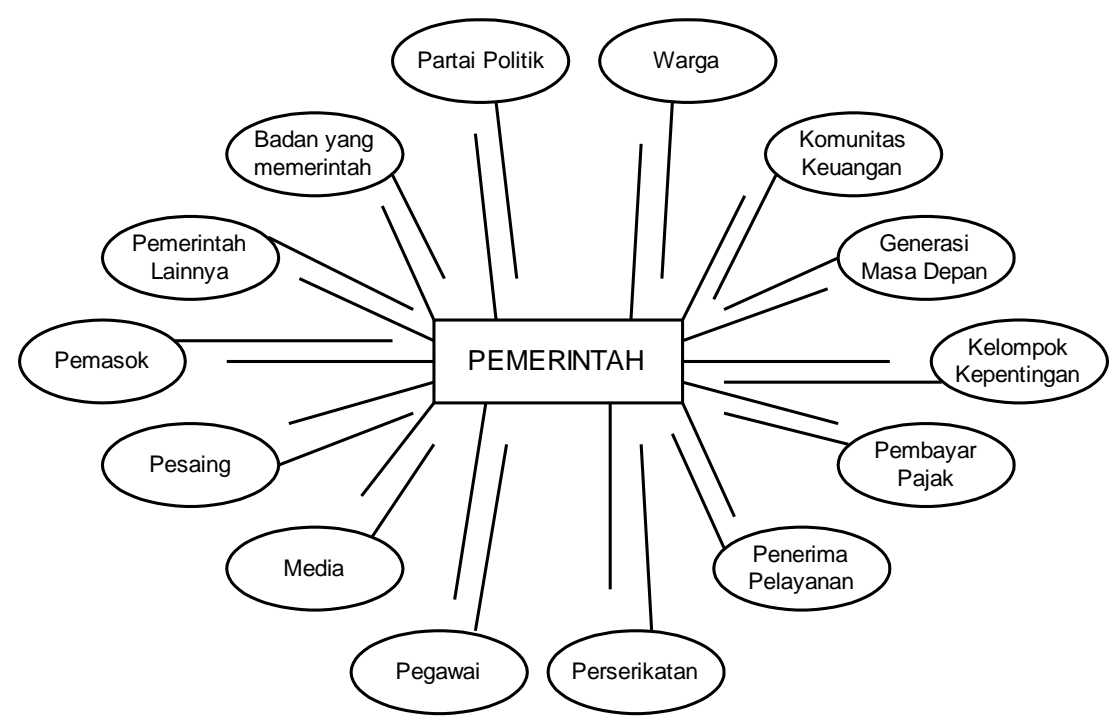

Gambar 2. Pengaruh Lingkungan terhadap Pemerintah sebagai Organisasi Publik, Bryson (2000:121)

\section{KEKUATAN LINGKUNGAN}

Dalam perkembangannya, lingkungan semakin menjadi penting bagi managemen publik. Dalam pelayanan publik, lingkungan dapat menggeserkan pelayanan publik yang berkeadilan dan transparan menjadi diskriminatif dan tertutup. Sejumlah elemen lingkungan yang dikemukakan Bryson diatas dapat menjadikan managemen berjalan efektif ataupun tidak. Oleh sebab itu diperlukan manager publik yang mampu mengendalikan jalannya managemen menjadi lebih efektif.

Lahirnya UU No 14/2008 tentang Keterbukaan Informasi Publik yang menuntut setiap aktivitas pemerintah diketahui publik tampaknya akan semakin berkembang jika sejumlah elemen lingkungan berpendapat sama akan hal tersebut. Sebaliknya, bila justru sejumlah elemen lingkungan yang digambarkan Bryson ada yang mendominasi managemen yang dijalankan 
pemerintah, maka persoalannya akan menjadi lain. Demikian halnya dengan karakteristik Good Governance yang dikeluarkan UNDP (Mardiasmo, 2002: 25), akan mendapat hambatan seandainya sejumlah elemen penting dalam lingkungan tidak mendukung kearah sana.

Kast and Rozenweig (1981:135) tampaknya menjawab bagaimana lingkungan memengaruhi manager publik. Dengan informasi yang disampaikan lingkungan, persepsi manager secara keseluruhan dapat dipengaruhi. Dalam banyak hal seperti nilai dan tujuan yang dikehendaki, struktur yang dibangun, pola hubungan antar-manusia dan proses managerial dapat berubah dengan input yang diberikan oleh lingkungan yang ada. Untuk memudahkannya, penulis gambarkan pandangan Kast sebagai berikut :

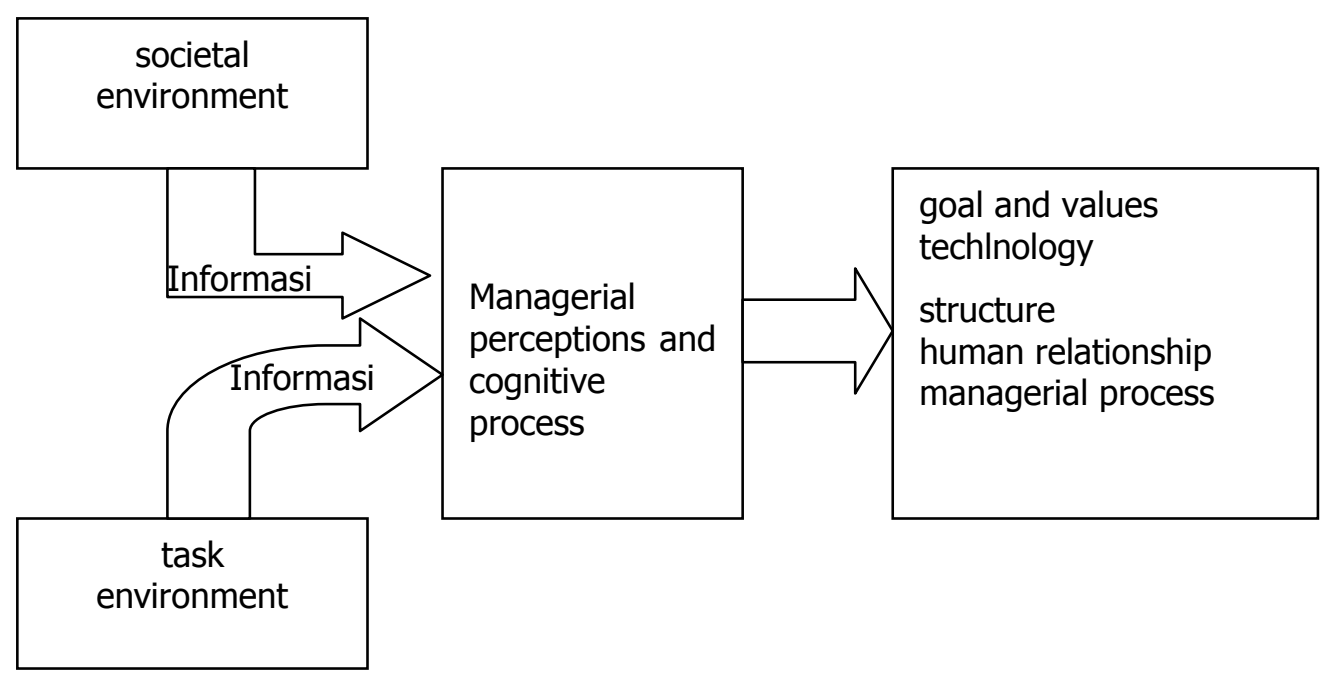

Gambar 3. Pola Hubungan antar-manusia dan Proses Manegerial, Kast and Rozenweig

Dari gambar di atas, dapat ditangkap bahwa kemampuan menyeleksi informasi penting bagi organisasi menjadi penting dilakukan oleh manager publik agar informasi yang didasarkan pada kepentingan sejumlah lingkungan dapat diminimalisir. Rosadi (1997: 22) berpendapat bahwa kemajuan masyarakat mendorong kemampuan untuk menuntut hal-hal yang lebih banyak dan lebih baik terhadap organisasinya. Hal demikian bisa berarti bahwa tingkat pendidikan aparat serta pejabat publik perlu terus ditingkatkan agar kapasitas dalam menyeleksi informasi secara sistematis menjadi lebih baik lagi. Tanpa kapasitas yang baik managemen publik akan tetap dikendalikan oleh sejumlah kepentingan, baik kepentingan lingkungan sosial maupun lingkungan kerjanya.

Beragam kasus yang muncul dalam praktik korupsi di tanah air sudah dapat menggambarkan bahwa sejumlah manager publik yang terlibat tidak lepas dari pengaruh yang diberikan oleh kedua lingkungan tersebut. Sayangnya persoalan tersebut muncul lebih didasarkan oleh kepentingan politik ataupun ekonomis dari lingkungan yang memengaruhinya. Bisa jadi keadaan tersebut seperti yang dikemukakan oleh
Dananjaya (1986:5) bahwa sejumlah kebutuhan memenangkan perseteruan dengan nilai yang dianut para manager publik. Dampaknya prilakunya tidak mendukung nilai namun justru mendukung kebutuhan yang dirasakannya.

Hasil penelitian di wilayah Bandung Utara, Sumaryana (2010:136) mencatat bahwa dalam lingkungan kerja, elemen warga dan generasi mendatang merupakan elemen yang patut mendapat perhatian penting untuk dijadikan pengendali prilaku manager publik. Rusaknya wilayah Punclut lebih disebabkan manager publik kota Bandung mampu dipengaruhi kedua lingkungan untuk meluluskan kepentingankepentingannya tanpa mempedulikan kepentingan masyarakat kota Bandung yang lebih luas. Dampaknya, RTRW yang dibuat pun menjadi macan kertas yang tumpul di lapangan.

Agar lingkungan dapat memengaruhi secara positif, persoalan pendidikan tampaknya menjadi penting untuk diperhatikan dalam seluruh elemen masyarakat dan pejabat publik. Sumaryana (2011:16) menyatakan bahwa pendidikan formal yang sudah overload perlu diimbangi dengan pendidikan informal yang diaktori keluarga. 
Dengan penguatan nilai keagamaan dan kearifan lokal, kebanggaan atas materi bisa ditekan terus. Tanpa upaya seperti itu, materialisme semakin menguat dan mendorong tingkat kebutuhan pada setiap pejabat ataupun aparat akan semakin besar sehingga akan mendorong pengabaian nilai.

\section{SIMPULAN}

Kapasitas dan jenjang pendidikan manager menjadi penting agar nilai yang ada dapat terus dikembangkan melampaui kebutuhan yang terus mendesak. Dengan cara demikian, lingkungan yang memengaruhi berdasarkan kepentingannya dapat disaring agar tidak merugikan publik. Pengawasan dan evaluasi peru ditempatkan sebagai elemen penting untuk meninjau pelaksanaan kerja di lapangan. Dengan demikian, sedikit saja penyimpangan yang terjadi dapat dikontrol lebih dini dan dilakukan upaya perbaikan. Sosial kontrol pun menjadi penting agar praktik menyimpang dalam managemen publik dapat diperbaiki dalam perjalanannya sehingga tujuan akhir tidak dikorbankan.

Tampaknya lingkungan yang memengaruhi buruk perlu diubah pula menjadi kekuatan yang mampu memperkokoh managemen publik sehingga managemen yang diperuntukkan bagi public service semakin memuaskan publiknya. Tidak berlebihan jika filosofis kasundaan dapat digunakan dalam kehidupan managerial yang diaktori orang Parahiangan. Cageur, bageur, bener, pinter dan singer ${ }^{2}$ merupakan kandungan yang harus dimiliki manager publik agar mampu ngadek sacekna, nilas saplasna ${ }^{3}$. Dengan kondisi demikian, managemen publik tidak akan mudah dikendalikan lingkungan untuk memenuhi kepentingan lingkungan itu sendiri, namun mengubahnya menuntun lingkungan untuk bisa lebih berguna dan menjadi mitra pemerintah.

\section{DAFTAR PUSTAKA}

Bryson. 2000. perencanaan Strategis Bagi Organisasi Sosial (edisi bahasa Indonesia). Yogyakarta : Pustaka Pelajar

Dananjaya. A. 1986. Sistem Nilai Manager Indonesia. Jakarta : PT Pustaka Binaman.
Donovan.F Cs. 1991. Managing Human Service Organizations. New York : Prentice Hall.

Griffin. 1996. Management. Toronto : Houhton Mifflin Company.

Mardiasmo. 2002. Otonomi \& Manajemen Keuangan Daerah. Yogyakarta : ANDI

Mintzberg. 1994. The Rise and Fall of Strategic Planning. New York: The Free Press.

Pasolong.H. 2008. Teori Administrasi Publik. Bandung : Alfabeta.

Rosadi.D. 1997. Sistem Perencanaan Terpadu Sebagai Suatu Determinan Peningkatan Pendapatan Asli Daerah Sektor Pajak (Suatu Kasus pada Dinas Pendapatan Daerah Tingkat II Se - Jawa Barat). Disertasi. Bandung : Program Pascasarjana.

Saefullah. A. D. 1992. The Impact of Population Mobility on Two Village Communities of West Java, Indonesia. Thesis. The Flinders University of South Australia.

Shafritz. 1992. Classics of Organization Theory (Third Edition). Pacific : Brook/Cole Publishing Company.

Sumaryana. A. 2010. Lingkungan dan Tata Ruang di Bandung Utara. Bandung : Unpad Press

. 2011. Faktor Lingkungan Dalam Kebijakan Publik. Jurnal JSP. Volume I, Nomor 1, Agustus 2011. Jatinangor: FISIPUnpad

UU No 14 Tahun 2008 Tentang Keterbukaan Informasi Publik.

\footnotetext{
${ }^{2}$ bahasa sunda : sehat, baik, benar, cerdas, terampi

${ }^{3}$ bahasa sunda : tegas
} 